\title{
Idioms for Collaborative Government Networks - Conceptualization and Applications to Seamless Services
}

\author{
Elsa Estevez ${ }^{1,2}$, Adegboyega Ojo ${ }^{1}$, and Tomasz Janowski ${ }^{1}$ \\ ${ }^{1}$ United Nations University - International Institute for Software Technology \\ Center for Electronic Governance \\ P.O. Box 3058, Macao SAR, China \\ ${ }^{2}$ National University of the South, Department of Computer Science and Engineering \\ $\{$ elsa, ao, tj\}@iist.unu.edu
}

\begin{abstract}
We examine the nature of Collaborative Networked Organizations in Government (CNO-G) and identify three core capabilities characterising such organizations - Partnership, Coordination and Integration. By considering these capabilities as idioms for the CNO-G domain, we define a conceptual model that expresses such capabilities using modeling abstractions provided by ARCON (A Reference Model for Collaborative Networks). Finally, we illustrate the resulting domain-specific modelling framework through the example of a concrete $\mathrm{CNO}-\mathrm{G}$ aimed at delivering a seamless public service.
\end{abstract}

Keywords: Modeling Collaborative Networked Organizations, Idioms for Collaborative Government Networks, Seamless Public Services.

\section{Introduction}

e-Government is defined as the use of Information and Communication Technologies (ICT) to achieve better government [1]: to provide customer-focused, efficient and reliable access to public services; to engage citizens in two-ways interactions with government; to support internal government operations; to enable cross-agency public services, etc. e-Government development increasingly aims at enabling collaboration and networking between agencies, with its highest maturity level - Seamless Government reached when strong collaboration leads to the whole public administration behaving as a single organization.

Seamless Government [2] promotes technology-enabled improvement through collaboration in government: between agencies from different levels and functions of government; between public, private and voluntary sectors; and between public administration systems. Collaboration in government offers clear benefits: better sharing of information by agencies, higher utilization of resources, more engaged policy-making, delivery of Seamless Public Services, etc. The latter, accessed through one-stop portals and organized into clusters, allow customers to specify their needs life situations for citizens or business episodes for businesses, and obtain services to fulfill such needs, unaware which agency or government level should be contacted. 
However, a transition from the operations carried out by a single agency to the operations by several collaborating agencies is difficult. What an agency is able to achieve on its own, considering existing legal frameworks, financial arrangements, working culture, organizational structure and technological preparation may be difficult to scale up to the cross-agency context. Building Collaborative Networked Organizations in Government (CNO-G) is challenging. The aim of this paper is to enable design and development of such networks through domain-specific modeling.

A number of frameworks exist to model Collaborative Networked Organizations (CNO) in general [3] including the Zachman's Frameworks, GERAM - Generalized Enterprise Reference Architecture, and ARCON - A Reference Model for Collaborative Networks. In particular, ARCON consolidates existing frameworks through generic abstractions to model basic elements of CNO [3][4]. It defines three modeling perspectives and three levels of abstraction to describe CNOs, covering both domain-independent and domain-specific aspects of such organizations.

This paper provides a domain-specific modeling framework of CNO-G based on ARCON, expressing CNO-G models as ARCON idioms for the e-Government domain, and demonstrating the application of the framework through a case study involving the delivery of a seamless public service by a concrete CNO-G. The paper makes three contributions: (1) it validates the applicability of ARCON for modeling $\mathrm{CNO}$ at the specific and implementation levels; (2) it provides rigorous descriptions of the core CNO-G concepts based on ARCON; and (3) it provides prescriptive models to guide the design and development of CNO-G.

The rest of the paper is organized as follows. Sections 2 and 3 outline CNO-G and the ARCON modeling framework respectively. Section 4 carries out domain-specific modeling for CNO-G based on ARCON: general representations (Section 4.1); specific models of the partnership, integration and coordination idioms (Section 4.2); and an implementation model for a CNO-G that delivers a seamless public service (Section 4.3). Section 5 outlines conclusions and directions for future work.

\section{Collaborative Government Networks}

Organizations today are faced with rapidly changing environments that require flexible structures and fast responses to emerging needs and opportunities. Networked organizations, characterized by team-based structures and highly decentralized control [5] emerged from hierarchical organizations in response to such changes.

In government, the adoption of networked organizations has been influenced by policy formation through interactions between the actors with different interests and goals [6], the need for individual agencies to overcome asymmetries [7], etc. The adoption was reinforced by the practices of [8]: the use of external entities to deliver services and fulfill policy goals; many agencies at different government levels providing integrated services; provisioning of customized services to respond to increasing customer demands for more choices; and acquisition of IT infrastructures that enable real-time collaboration with external partners. In response, different network patterns have emerged [9][8]: joined-up government, whole-of-government, public-private partnerships, etc. leading to the benefits of: higher performance, 
innovation in policy making, and stability of relationships allowing network actors to combine their knowledge, experience and resources in new and productive ways [7].

Two types of collaboration are carried out within government networks - vertical and horizontal [10]. The former involves collaboration across levels of government and includes (1) information seeking and (2) adjustment seeking. The latter involves actors at the same level of authority and includes: (3) policy making and strategy making, (4) resource exchange and (5) project-based work. See Table 1.

Table 1. CNO-G collaboration types

\begin{tabular}{l|l|l}
\hline NO & TYPE & EXAMPLE \\
\hline 1 & Information seeking & interpretation of standards and rules \\
\hline 2 & Adjustment seeking & policy changes \\
\hline 3 & Policy and strategy making & engaging in policy making \\
\hline 4 & Resource exchange & seeking financial resources or incentives \\
\hline 5 & Project-based work & partnership for projects and seeking resources \\
\hline
\end{tabular}

The structure of government networks plays a major role in attaining the desired goals, including a system of authority that determines how the partners coordinate their actions and use resources to achieve their goals [11]. In general, coordination is deployed to ensure that the network's functional and organizational resources create the maximum value, implemented through structural decisions related to control and oversight [5][11][12]. Control mechanisms are: (1) providing the context for action, (2) providing advice and information to support action and (3) authorization or direct supervision over action execution [6]. In addition, control can take place within an overall coordination context; from direct supervision; through standardization of work processes, outputs and skills; to mutual adjustment by network partners [6]. Specific instruments for coordination and control are budget-making and oversight processes to fund network initiatives.

Guided by collaboration goals and activity types, the CNO-G design fundamentally relies on: (1) the partnership configuration required for the collaboration activity; (2) the integration through shared functions implemented as services and processes, and supporting shared resources; and (3) the overall coordination mechanism to optimize the structure, function and network resources towards achieving collaboration goals.

\section{Modeling CNO in ARCON}

The ARCON modeling framework includes abstractions to capture CNO entities and their relationships [3]. The framework defines three modeling perspectives: (1) life cycle stages, (2) environment characteristics and (3) modeling intents. The first comprises: creation, operation, evolution, metamorphosis and dissolution. The second identifies internal aspects of the CNO (endogenous elements) and interactions with the environment (exogenous interactions). The third defines modeling layers: general representation, specific modeling, and implementation modeling. See Fig. 1. 


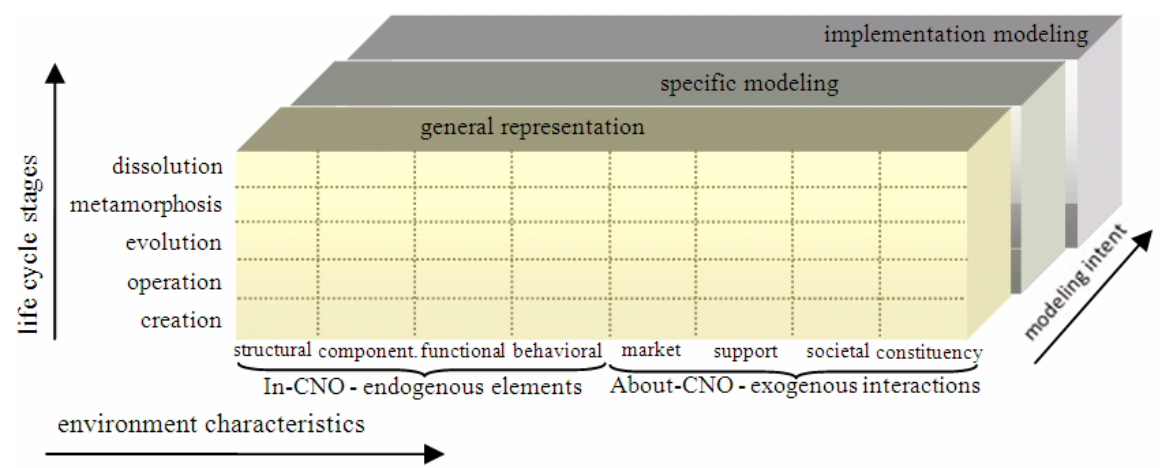

Fig. 1. ARCON Reference Model

The environmental aspects are divided into: endogenous elements - structural, componential, functional and behavioral (In-CNO); and exogenous interactions market, support, societal and constituency (About-CNO). In the following, we focus on the In-CNO subspace as relevant to CNO-G. The subspace includes four types of endogenous elements: (1) Structural - identifies the constituting elements of CNO like members and their relationships and roles, and other member- and networkrelated attributes; (2) Componential - tangible and intangible resources of CNO such as hardware and software, human resources, information and knowledge resources, and meta-data repositories owned by CNO; (3) Functional - the elements that enable the operations of $\mathrm{CNO}$, such as processes and methodologies; and (4) Behavioral the elements that drive or constraint the behavior of CNO members, for example the elements specifying prescriptive and mandatory behaviors, constraints and conditions, and contracts and cooperation agreements.

\section{Modeling CNO-G Based on ARCON}

This section shows how the structural, componential, functional and behavioral aspects of CNO-G and their collaboration goals (Section 2) can be captured by three domain-specific concepts - partnership, integration and coordination, treated as idioms for the application of ARCON (Section 3) to the e-Government domain.

\subsection{General Representation}

In order to achieve collaboration goals, CNO-G members create partnerships to identify the members involved in collaboration and their roles, and integrate processes to enable the execution of multi-organizational processes as part of Seamless Government. Partnership and Integration extend Structural and Functional dimensions of ARCON respectively. Both dimensions match: structures are defined to fulfill processes, processes are assigned to members, and both support members to achieve collaboration goals. Integration is defined by extending Componential aspects and integrated resources are supplied to execute integrated functions. Coordination is required to shape Partnership and guide Integration, but the type of Partnership 
influences the way Coordination is performed; Coordination is modeled using the Behavioral dimension of ARCON. The model is depicted on the left side of Figure 2, with the corresponding UML Class Diagram on the right. The latter includes: CNO-G Collaboration Goal is implemented through Partnership, Integration and Coordination; Partnership contributes to Integration; Coordination governs Partnership and Integration; all apply ARCON interfaces - Partnership (Structural), Integration (Componential and Functional) and Coordination (Behavioral).

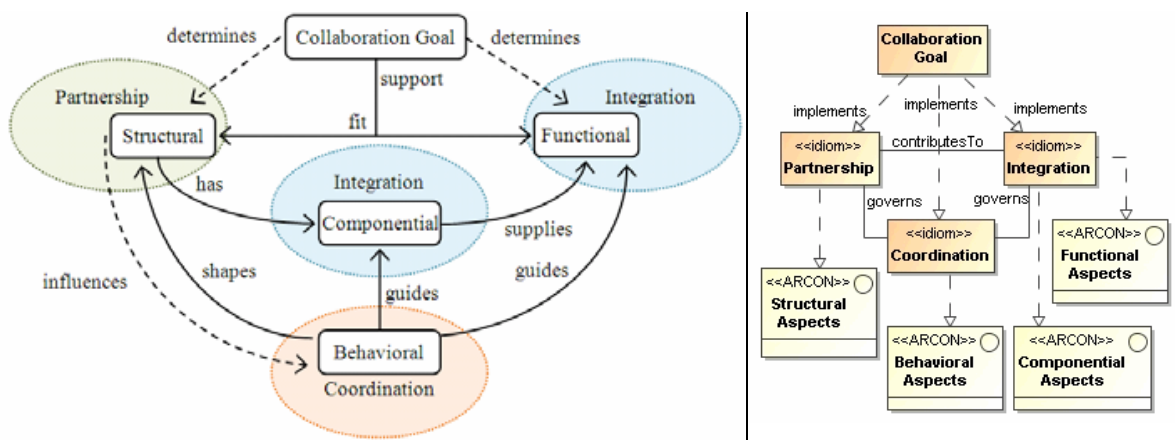

Fig. 2. CNO-G Capabilities - ARCON Meta-Model and its Formalization

\subsection{Specific Modeling}

At a lower level of abstraction, corresponding to the ARCON specific modeling level, the Partnership, Integration and Coordination capabilities are modeled using UML Class Diagrams, with the corresponding idioms depicted in Figures 3, 4 and 5.

Partnership consists of Partners, each determining other Partners, having Partner Role and Partner Responsibility, and contributing to Shared Resources and Shared Functions (part of Integration). Partner is ARCON Actor and Partner Role is ARCON Role. Partnership has different types (Partnership Type): Public-Private Partnership, Inter-Agency Collaboration and Multi-Stakeholder Partnership. See Figure 3.

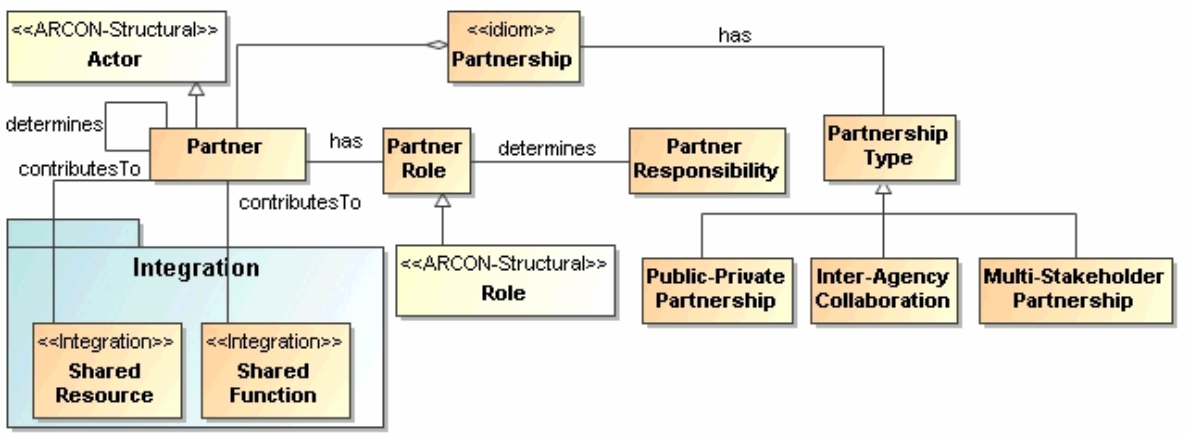

Fig. 3. CNO-G Modeling - Partnership Idiom 
According to Figure 4, Integration produces Shared Resources and Shared Functions. Generalizing ARCON elements, Shared Resources may be Technological Hardware and Software; Human - Human Resources; or Informational - Data, Information and Ontology. Shared Functions are executed by Shared Processes which can be Core or Auxiliary, both subtypes of the corresponding ARCON elements. Finally, Integration applies Integration Methods as a kind of ARCON Methodology.

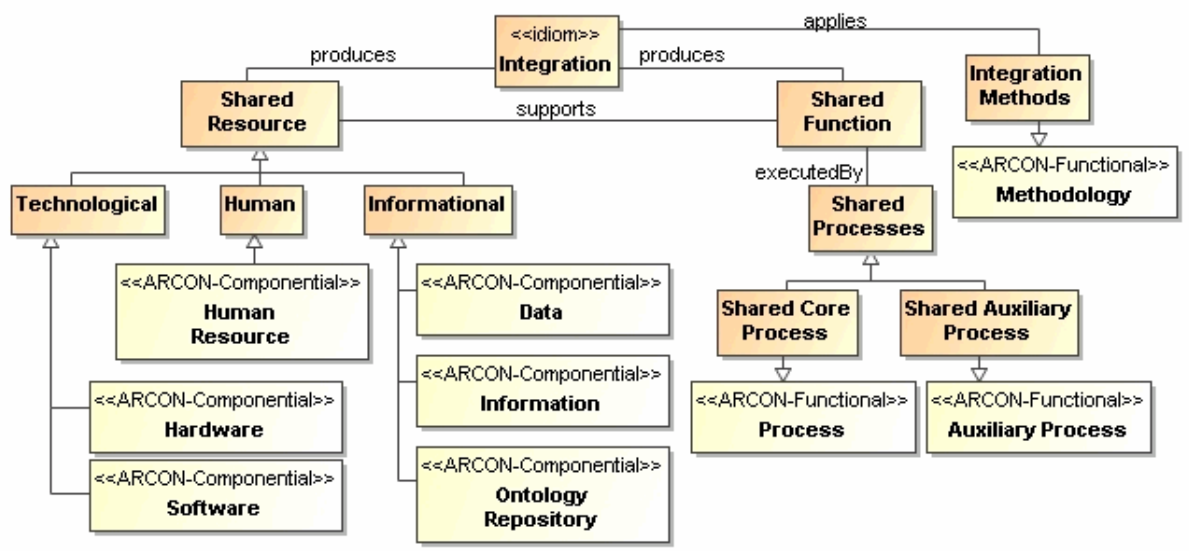

Fig. 4. CNO-G Modeling - Integration Idiom

According to Figure 5, Coordination is carried out by a Central Unit which is of two possible types: Organizational Structure - created as a government agency, or Committee - group of top-level decision makers. Both are ARCON Actors. A Central Unit issues Recommendations, enforces Standards and Guidelines, and defines Collaboration Frameworks. Recommendations are a sub-type of ARCON Prescriptive Behavior, Standards and Guidelines are subtypes of ARCON Obligatory Behavior, while Collaboration Frameworks is a subtype of ARCON Cooperation Agreement.

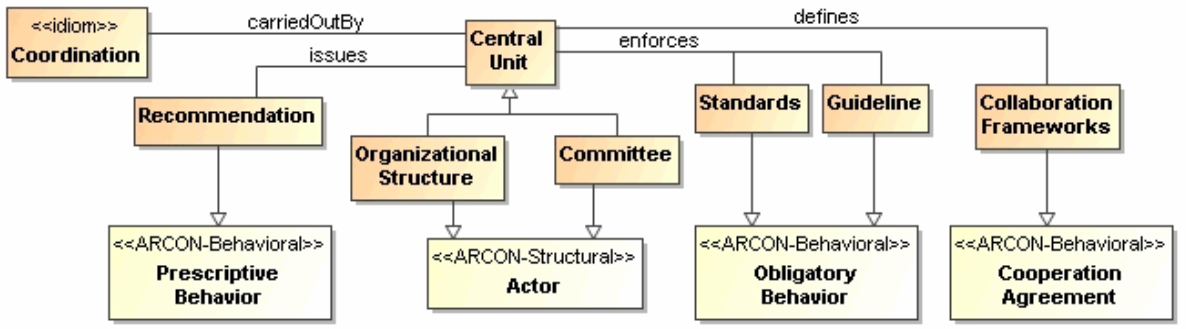

Fig. 5. CNO-G Modeling - Coordination Idiom

\subsection{Implementation Modeling}

As an implementation model, we present a real-life CNO-G comprising a set of agencies of the Government of Macao SAR, jointly issuing business licenses for 
running food and beverage establishments. The Civic and Municipal Affairs Bureau (IACM) is responsible for issuing such licenses, relying on other agencies to carry out inspections, provide technical opinions, and check conformance to relevant laws. Depicted in Figure 6, the application process comprises [14]: (1) Submission - an applicant submits an application form and supporting documents; (2) Completeness Assessment - IACM checks completeness of the application and notifies the applicant about any missing parts; (3) Evaluation - IACM requests opinions from: Labor Bureau about safety of the working environment, Public Works Bureau about construction plans, Cultural Affairs Bureau about outdoor landscaping for cultural heritage, Fire Brigade about fire prevention and Health Bureau about sanitary conditions; (4) Decision Making - IACM makes a decision based on the opinions; and (5) Follow-up - IACM notifies the applicant and issues the license if granted.

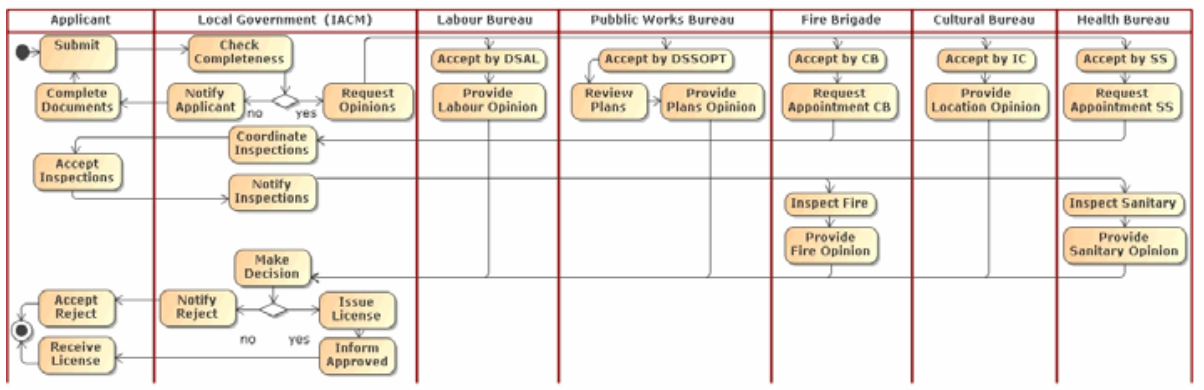

Fig. 6. Implementation Modeling - Licensing Service Workflow

Based on this example, the implementation model for Partnership is presented as a UML Object Diagram in Figure 7. Partnership (Inter-Agency Collaboration type) comprises: IACM, LabourBureau, PublicWorksBureau, FireBrigade, CulturalBureau and HealthBureau. IACM plays the role of licensingAgency and is responsible for issuingLicense. LabourBureau and CulturalBureau play the role of technicalAdvisor, responsible for revising TechnicalDocument and providingOpinion. Shared functions include issuing TechnicalOpinion by PublicWorksBureau, and controlFirePreventions by FireBrigade. Building inspectors are shared resources by PublicWorksBureau.

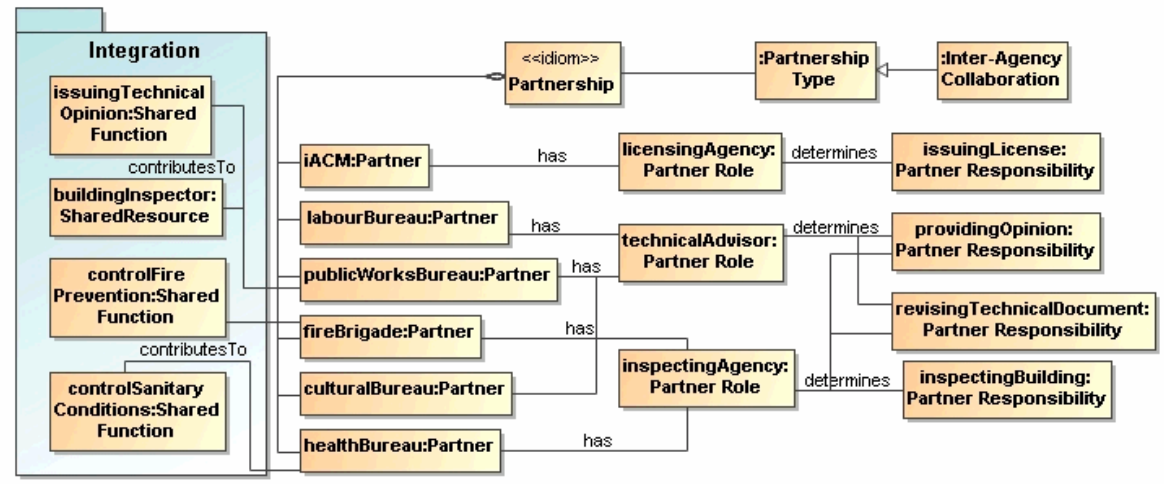

Fig. 7. Implementation Modeling - Partnership for Licensing CNO-G 


\section{Conclusions}

We introduced Collaborative Networked Organizations in Government (CNO-G) as a kind of Collaborative Networked Organizations (CNO); identified a set of capabilities characterising them - partnership, integration and coordination; defined them as idioms for the CNO-G domain; and modeled them based on ARCON. The main contributions of this work are: (1) validating ARCON in a specific domain; (2) modeling CNO-G capabilities based on ARCON's three abstraction layers; and (3) providing three idioms as prescriptive models for CNO-G design and development. We argue that the model is valid independent of the government structure involved the case study does not depend on the level of government and the agencies could be replaced by other kinds of organizations. In the future, we plan to identify and specify additional idioms for CNO-G, focusing on the exogenous interactions of the AboutCNO sub-space, and validating these idioms for different CNO-G collaboration goals.

\section{References}

1. Field, T., Muller, E., Law, E.: The e-Government Imperative. Organization for Economic Co-operation and Development (2003) ISBN 92-64-10117-9

2. Office of Public Service, Merit and Equity, Queensland Government. Seamless Government: Improving Outcomes for Queenslanders (2004), http://www.opsc . qldgov.au/library/docs/resources/publications/Notices/Seamle ssGovernment.pdf

3. Camarinha-Matos, L.M., Afsarmanesh, H.: On reference models for collaborative networked organizations. Int. J. Production Research 46(9), 2453-2469 (2008)

4. Camarinha-Matos, L.M., Afsarmanesh, H. (eds.): Collaborative Networks: Reference Modeling. Springer, Heidelberg (2008) ISBN 978-0-387-79425-9

5. Ahuja, M., Carley, K.: Network Structure in Virtual Organizations. Organization Science 10(6), 741-757 (1999)

6. Klijn, E.: Networks and Interorganizational Management - Challenging, Steering, Evaluation, and the Role of Public Actors in Public Management. In: Ferlie, E., et al. (eds.) The Oxford Handbook of Public Management. Oxford University Press, Oxford (2005)

7. Fountain, J.E.: Building the Virtual State - Information Technology and Institutional Change. Brookings Institution Press, Washington (2001)

8. Goldsmith, S., Eggers, W.: Governing by Network - The New Shape of the Public Sector. The Brookings Institution Press, Washington (2004)

9. Christensen, T., Laegreid, P.: The Whole-of-Government Approach to Public Sector Reform. Public Administration Review (November/December 2007)

10. Agranoff, R., McGuire, M.: Collaborative Public Management - New Strategies for Local Governments. Georgetown University Press, Washington (2003)

11. Jones, G.R.: Organizational Theory - Text and Cases. Prentice-Hall Inc., NJ (2001)

12. Powell, W.: Neither Market nor Hierarchy: Network Forms of Organization. Research in Organizational Behaviour 12, 295-336

13. Camarinha-Matos, L.M., Afsarmanesh, H.: A comprehensive modeling framework for collaborative networked organizations. Journal of Intelligent Manufacturing 18(5), 527615 (2007)

14. Instituto para os Assuntos Civicos e Municipais (IACM), One-Stop Licensing Service for Food and Beverage Establishments, IACM, Macao SAR Government, China (2004) 